\title{
Successful use of equine anti-thymocyte globulin (ATGAM) for fulminant myocarditis secondary to nivolumab therapy
}

\author{
Rebecca Y Tay ${ }^{1}$, Elizabeth Blackley ${ }^{1}$, Catriona McLean ${ }^{2,3}$, Maggie Moore ${ }^{1}$, Peter Bergin ${ }^{4}$, Sanjeev Gill ${ }^{1}$ \\ and Andrew Haydon*,1,3 \\ ${ }^{1}$ Department of Medical Oncology, Alfred Health, Melbourne, Victoria 3004, Australia; ${ }^{2}$ Department of Anatomical Pathology, \\ Alfred Health, Melbourne, Victoria 3004, Australia; ${ }^{3}$ Monash University, Melbourne, Victoria 3800, Australia and ${ }^{4}$ Heart Centre, \\ Alfred Health, Melbourne, Victoria 3004, Australia
}

Background: Immune-mediated myocarditis is an uncommon adverse effect of immune checkpoint inhibition and is associated with a high rate of mortality.

\begin{abstract}
Methods: In this reported case, a 64-year-old woman with right temporo-parietal glioblastoma IDH-WT was treated with nivolumab, temozolomide and radiation therapy on a clinical trial. She developed malignant arrhythmias secondary to histologically confirmed severe immune-mediated myocarditis. She was treated with equine anti-thymocyte globulin (ATGAM) due to development of malignant arrhythmias refractory to high-dose corticosteroids.
\end{abstract}

Results: This report describes the only case of immune-mediated myocarditis treated with ATGAM resulting in a favourable outcome.

Conclusions: Use of ATGAM should be considered in cases of steroid-refractory immune-mediated myocarditis and administered in close consultation with a cardiac transplant team experienced in the use of this agent.

Immune checkpoint inhibitors have revolutionised the treatment of malignancy by facilitating enhanced anti-tumour immune response. Nivolumab, an anti-programmed death-1 (PD-1) antibody has been established as a standard of care in melanoma (Larkin et al, 2015; Robert et al, 2015; Weber et al, 2015), lung (Borghaei et al, 2015), renal cell (Motzer et al, 2015), bladder (Sharma et al, 2017) and head and neck (Ferris et al, 2016) cancers and is being tested in clinical trials for many other tumour types.

Nivolumab, like other PD-1 directed antibodies, releases restraint on the innate immune system. This unique mechanism of action gives rise to a side-effect profile distinct to that of traditional cytotoxic chemotherapy agents. Toxicities are autoimmune in nature and most commonly include rash, endocrinopathies, colitis, hepatitis and pneumonitis. Less frequently reported side-effects are myasthenic syndrome, nephritis, myopathies and myocarditis (Naidoo et al, 2015).

Steroids are currently the mainstay of treatment for the serious toxicities from immunotherapy. In steroid-refractory cases, other immunosuppressants such as infliximab, mycophenolate and intravenous immunoglobulin have been trialled with variable success (Postow, 2015).

Recent case reports of immune-mediated myocarditis reveal the extremely high mortality of this particular toxicity (Johnson et al, 2016). Death due to refractory arrhythmias is the outcome in most reported cases (Heinzerling et al, 2016; Johnson et al, 2016). Here, we describe the only case of immune-mediated myocarditis treated with intravenous anti-thymocyte globulin (ATGAM) resulting in a favourable outcome.

${ }^{\star}$ Correspondence: Dr A Haydon; E-mail: Andrew.Haydon@monash.edu

Received 27 March 2017; revised 16 May 2017; accepted 11 July 2017; published online 10 August 2017

(C) 2017 Cancer Research UK. All rights reserved 0007 - 0920/17 


\section{CASE REPORT}

A 64-year-old woman with no prior history of autoimmune or cardiac disease was diagnosed with right temporo-parietal glioblastoma IDH-WT. She was consented and enroled onto the CheckMate CA209-548 clinical trial (A Randomised Phase 2 Single Blind Study of Temozolomide plus Radiation Therapy combined with Nivolumab or Placebo in Newly Diagnosed Adult Subjects with MGMT-Methylated (tumour O6-methylguanine DNA methyltransferase) Glioblastoma). Eight days after her second trial drug infusion, she presented with diplopia, diffuse myalgias and proximal weakness. No chest pain, dypsnoea, palpitations or fever was reported.

On admission, creatine kinase was $3538 \mathrm{U}$ per litre (normal range $60-285 \mathrm{U}$ per litre) and troponin I was $8375 \mathrm{ngl}^{-1}$ (normal range $<26)$. Electrocardiograph (ECG) revealed ventricular bigeminy with frequent ventricular ectopics. Echocardiogram demonstrated normal left ventricular size with moderate systolic dysfunction and a reduced left ventricular ejection fraction of 37\%. Electromyography excluded neuromuscular junction pathology. Viral serology for herpes simplex virus type 1 and 2, varicella zoster virus, cytomegalovirus, enterovirus and adenovirus were all negative.

A clinical diagnosis of autoimmune myositis and myocarditis was made. She commenced intravenous methylprednisolone $500 \mathrm{mg}$ daily for 3 days before tapering to oral prednisolone $100 \mathrm{mg}$ daily. A single dose of intravenous infliximab $5 \mathrm{mg} \mathrm{kg}^{-1}$ was administered on Day 2 of admission given its use in previous case reports. Over the subsequent days, persistent ventricular bigeminy and episodic non-sustained ventricular tachycardias was treated with amiodarone and low-dose beta blocker therapy. Following this treatment, she remained haemodynamically stable with cardiac monitoring, confirming intermittent ventricular bigeminy with no further malignant arrhythmias.

On day 8 of admission, her clinical condition acutely deteriorated with sustained conscious ventricular tachycardia and haemodynamic compromise. She required direct current cardioversion that resulted in complete heart block with a junctional escape rhythm. Subequently, an emergency cardiac biopsy, coronary angiogram and placement of a temporary pacing wire was undertaken. Cardiac biopsy (taken following administration of corticosteroids and infliximab) revealed multifocal lymphocytic $(\mathrm{CD} 3+, \mathrm{CD} 8+$ predominant with mixed $\mathrm{CD} 3+\mathrm{CD} 4+$ subtypes) and histiocytic infiltrates associated with focal areas of myocyte necrosis (Figures 1 and 2; panel A) consistent with an immune-mediated myocarditis. All immunohistochemistry was performed using DAKO-Omnis apparatus with ready-to-use DAKO antibodies to CD3, CD4, CD8, CD20 and CD68. Coronary angiogram was unremarkable.

After consultation with the heart failure/cardiac transplantation unit, the decision was made to commence equine ATGAM therapy with a view to depletion of T-lymphocytic infiltrate as used in cellular rejection of cardiac allografts.

ATGAM administration was per local protocol for acute cellular rejection consisting of ATGAM $500 \mathrm{mg}$ on day 1, titrating the dose by $250 \mathrm{mg}$ increments to daily CD2/3 levels (aiming for levels of $50-100 / \mu \mathrm{l})$ for a total of 5 days. During this time, the patient remained in a ventricular paced rhythm. Repeat echocardiogram showed a mildly improved left ventricular ejection fraction of $43 \%$.

Clinical and biochemical improvement occurred within three days of ATGAM therapy with resolution of ventricular arrhythmias and near normalisation of cardiac enzymes occurring by day 5 of ATGAM initiation. ECG confirmed return to sinus rhythm with an incomplete right bundle branch block and the temporary pacing wire was removed. Mycophenolate $1 \mathrm{gm}$ twice daily was commenced on day 5 of ATGAM therapy. Prednisolone $100 \mathrm{mg}$ daily was continued throughout ATGAM dosing.

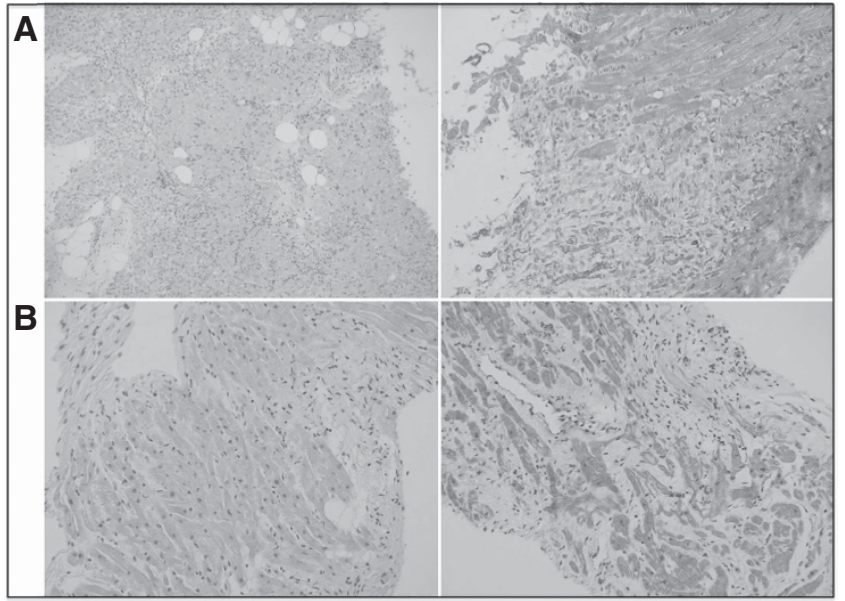

Figure 1. Comparison of endomyocardial biopsy histology. Comparison haemoatoxylin and eosin (left) and Masson-trichrome stain (right) of original endomyocardial biopsy (A) and 6-week biopsy (B) showing a marked reduction in lymphocytes and patchy early fibrosis by 6 weeks. At $\times 200$ magnification.

A second biopsy performed 10 days later demonstrates pathologic improvement with patchy lymphohistiocytic myocarditis with significantly less-myocyte necrosis. A third biopsy at 6 weeks after presentation revealed patchy foci of fibrosis, scant inflammatory cells and intervening viable myocytes in keeping with evidence of early repair (Figures 1 and 2; panel B).

Following removal of temporary pacing wires, the patient was able to complete a full course of radiotherapy for her glioblastoma. She was taken off study, unblinded and nivolumab permanently discontinued. Temozolamide concurrent with radiotherapy was also discontinued given the potential for prolonged cytopenias in the setting of ATGAM therapy.

Mycophenolate $1 \mathrm{gm}$ twice daily was continued for 4 weeks then slowly weaned and ceased over a 12 week period. Prednisolone $100 \mathrm{mg}$ was weaned by $5 \mathrm{mg}$ every week. The diplopia and proximal muscle weakness that characterised her myopathy at presentation markedly improved with the institution of intravenous steroids and infliximab.

It is now 6 months since her presentation. Performance status has improved and she is now independent with all activities of daily living. There is no evidence of disease progression on her most recent cerebral magnetic resonance imaging. She is currently in her second cycle of standard temozolomide on a monthly schedule.

\section{DISCUSSION}

Immune-mediated cardiotoxicity is an uncommon adverse effect of immune checkpoint inhibition resulting in a spectrum of events that affect the myocardium including myocarditis, cardiomyopathy and myocardial fibrosis. (Heinzerling et al, 2016).

Interrogation of safety databases report the incidence of immune-mediated myocarditis to be $0.06 \%(n=10 / 17620)$ for single-agent nivolumab and $0.27 \%(n=8 / 2974)$ for combination nivolumab/ipilimumab. Combination checkpoint blockade is associated with both a higher incidence and severity of immunemediated myocarditis (Johnson et al, 2016). The true incidence of immune-mediated myocarditis may be grossly underestimated with serial cardiac monitoring with ECGs or troponin levels not routinely undertaken in clinical practice.

Immunotherapy-induced myocarditis has a highly variable clinical presentation. Symptoms range from subclinical disease to 


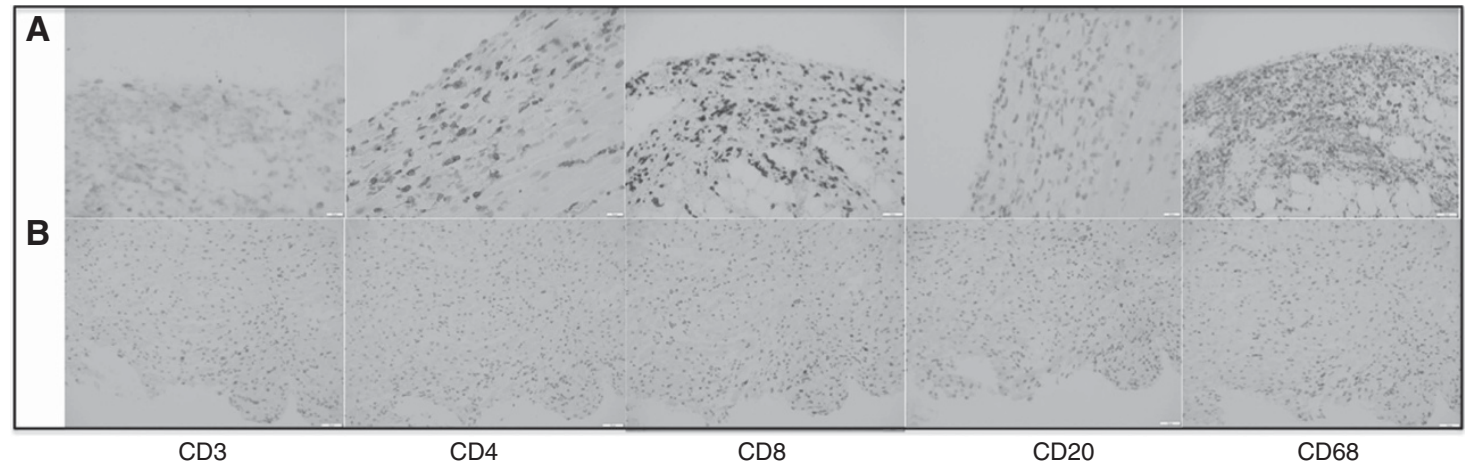

Figure 2. Comparison of endomyocardial biopsy immunoperoxidase stains. Comparison immunoperoxidase stains for CD3, CD4, CD8, CD20 and CD68 of original endomyocardial biopsy (A) and 6-week biopsy (B) showing a marked reduction over 6 weeks in the initial T-cell-rich CD8 $>$ CD4 and histiocytic infiltrate (CD68), with no B cells (CD20). At $\times 200$ magnification.

chest pain, cardiac failure, cardiogenic shock, arrhythmias and sudden death (Läubli et al, 2015; Heinzerling et al, 2016; Johnson et al, 2016). The onset of symptoms tend to occur within the first few weeks of initial anti PD-1 and/or anti-CTLA4 therapy with the median time to onset of symptoms being 17 days from the first infusion (Johnson et al, 2016). Although an uncommon event, the importance of identifying immune-mediated myocarditis is underscored by its potentially fatal sequelae.

Histopathological examination of the endomyocardium typically demonstrates a patchy CD3-positive lymphocytic infiltrate, involving the myocardium and conduction system. Drug-induced immune-mediated myocarditis can share some morphologic similarity but usually contains eosinophils with other causes of a multifocal lymphocytic myocarditis, including severe cellular allograft rejection post cardiac transplantation, severe viral myocarditis and connective tissue disease associated lymphocytic myocarditis.

Corticosteroids are used to manage immune-related adverse events through suppression of lymphocyte activity and inhibition of cytokine synthesis. High-dose corticosteroids have been initiated in the majority of reported cases of immune-mediated myocarditis. Induction doses range from $1-2 \mathrm{mg} \mathrm{kg}^{-1}$ methylprenisolone, followed by a taper to oral corticosteroids (Heinzerling et al, 2016; Johnson et al, 2016). Benefit from corticosteroid therapy should occur within days and can be monitored with serial troponin and creatinine kinase levels.

High-dose corticosteroid therapy alone may not be sufficient to resolve immune-related cardiac toxicity with multiple published reports, (Heinzerling et al, 2016; Johnson et al, 2016) describing immune-mediated myocarditis treated with corticosteroids alone resulting in death owing to the development of malignant arrhythmias or cardiac failure.

Infliximab is a chimeric IgG 1 monoclonal antibody that blocks tumour necrosis factor-alpha, a proinflammatory cytokine implicated in the pathogenesis of immune-mediated colitis. Infliximab is indicated for use in steroid refractory immune-related colitis secondary to checkpoint inhibition (Pagès et al, 2013). Early introduction of infliximab for severe cases of immune-related colitis is also supported by the literature (Merrill et al, 2014). No published cases of immune-mediated myocarditis have been successfully treated with infliximab, suggesting tumour necrosis factor-alpha is not a primary driver of T-cell hyperactivation within the myocardium.

ATGAM is a polyclonal antibody derived by immunisation of horses with lymphoid cells derived from the thymus or cultured B-cell lines. Labelled use includes treatment of allograft rejection and aplastic anaemia (Lexicomp, Inc, 2017). ATGAM reverses acute allograft rejection by inducing $\mathrm{T}$ lymphocyte depletion via complement-dependent cell lysis. ATGAM has been successfully used to treat at least two cases of severe ipilimumab-induced hepatotoxicity (Chmiel et al, 2011; Ahmed et al, 2015). No other data are published regarding the use of ATGAM for immunerelated adverse events, including cases of immune-mediated cardiotoxicity.

ATGAM is administered via a central line with dosing titrated to $\mathrm{CD} 2$ and CD3 levels. We advise that ATGAM is administered under the guidance of a cardiac transplant unit experienced in treating acute allograft rejection.

In this case, we attribute the successful termination of malignant arrhythmias and improvement in cardiac function to the administration of ATGAM given the temporal relationship between the time of infusion and clinical improvement. We hypothesise that ATGAM resulted in the rapid reduction of T-cell hyperactivation as demonstrated by reduction of lymphocytic infiltration seen on serial cardiac biopsies and the near normalisation of troponin levels.

\section{CONCLUSION}

Immune-mediated myocarditis is a rare, often fatal immunerelated adverse effect of checkpoint inhibitor therapy. This case demonstrates that the use of ATGAM should be considered in cases of steroid-refractory immune-mediated myocarditis. ATGAM should be administered in close consultation with a cardiac transplant team experienced in the use of this agent.

\section{CONFLICT OF INTEREST}

The authors declare no conflict of interest.

\section{REFERENCES}

Ahmed T, Pandey R, Shah B, Black J (2015) Resolution of ipilimumab induced severe hepatotoxicity with triple immunosuppressants therapy. BMJ Case Rep: pii: bcr2014208102. Available at: http://doi.org/10.1136/ bcr-2014-208102.

Borghaei H, Paz-Ares L, Horn L, Spigel DR, Steins M, Ready NE, Chow LQ, Vokes EE, Felip E, Holgado E, Barlesi F, Kohlhäufl M, Arrieta O, Burgio MA, Fayette J, Lena H, Poddubskaya E, Gerber DE, Gettinger SN, Rudin CM, Rizvi N, Crinò L, Blumenschein GR Jr (2015) Nivolumab versus docetaxel in advanced nonsquamous non-small-cell lung cancer. $N$ Engl J Med 373: 1627-1639.

Chmiel KD, Suan D, Liddle C, Nankivell B, Ibrahim R, Bautista C, Thompson J, Fulcher D, Kefford R (2011) Resolution of severe 
ipilimumab-induced hepatitis after antithymocyte globulin therapy. J Clin Oncol 29: 237-240.

Ferris RL, Blumenschein Jr G, Fayette J, Guigay J, Colevas AD, Licitra L, Harrington K, Kasper S, Vokes EE, Even C, Worden F, Saba NF, Iglesias Docampo LC, Haddad R, Rordorf T, Kiyota N, Tahara M, Monga M, Lynch M, Geese WJ, Kopit J, Shaw JW, Gillison ML (2016) Nivolumab for recurrent squamous-cell carcinoma of the head and neck. N Engl J Med 375: 1856-1867.

Heinzerling L, Ott PA, Hodi FS, Husain AN, Tajmir-Riahi A, Tawbi H, Pauschinger M, Gajewski TF, Lipson EJ, Luke JJ (2016) Cardiotoxicity associated with CTLA4 and PD1 blocking immunotherapy. J Immunother Cancer 4: 50.

Johnson DB, Balko JM, Compton ML, Chalkias S, Gorham J, Xu Y, Hicks M, Puzanov I, Alexander MR, Bloomer TL, Becker JR, Slosky DA, Phillips EJ, Pilkinton MA, Craig-Owens L, Kola N, Plautz G, Reshef DS, Deutsch JS, Deering RP, Olenchock BA, Lichtman AH (2016) Fulminant myocarditis with combination immune checkpoint blockade. N Engl J Med 375: 1749-1755.

Larkin J, Chiarion-Sileni V, Gonzalez R, Grob JJ, Cowey CL, Lao CD, Schadendorf D, Dummer R, Smylie M, Rutkowski P, Ferrucci PF, Hill A, Wagstaff J, Carlino MS, Haanen JB, Maio M, Marquez-Rodas I, McArthur GA, Ascierto PA, Long GV, Callahan MK, Postow MA (2015) Combined nivolumab and ipilimumab or monotherapy in untreated melanoma. N Engl J Med 373: 23-34.

Lexicomp, Inc (2017) Antithymocyte globulin (equine, Atgam): Drug information. Lexicomp, Inc.

Läubli H, Balmelli C, Bossard M, Pfister O, Glatz K, Zippelius A (2015) Acute heart failure due to autoimmune myocarditis under pembrolizumab treatment for metastatic melanoma. J Immunother Cancer 3: 11.

Merrill SP, Reynolds P, Kalra A, Biehl J, Vandivier RW, Mueller SW (2014) Early administration of infliximab for severe ipilimumab-related diarrhea in a critically ill patient. Ann Pharmacother 48: 806-810.

Motzer RJ, Escudier B, McDermott DF, George S, Hammers HJ, Srinivas S, Tykodi SS, Sosman JA, Procopio G, Plimack ER, Castellano D,

Choueiri TK, Gurney H, Donskov F, Bono P, Wagstaff J, Gauler TC, Ueda T, Tomita Y, Schutz FA, Kollmannsberger C, Larkin J (2015)
Nivolumab versus everolimus in advanced renal-cell carcinoma. $N$ Engl J Med 373: 1803-1813.

Naidoo J, Page DB, Li BT, Connell LC, Schindler K, Lacouture ME, Postow MA, Wolchok JD (2015) Toxicities of the anti-PD-1 and anti-PDL1 immune checkpoint antibodies. Ann Oncol 26: 2375-2391.

Pagès C, Gornet JM, Monsel G, Allez M, Bertheau P, Bagot M, Lebbé C, Viguier M (2013) Ipilimumab-induced acute severe colitis treated by infliximab. Melanoma Res 23: 227-230.

Postow MA (2015) Managing immune checkpoint-blocking antibody side effects. Am Soc Clin Oncol Educ Book 35(76): 76-83.

Robert C, Long GV, Brady B, Dutriaux C, Maio M, Mortier L, Hassel JC, Rutkowski P, McNeil C, Kalinka-Warzocha E, Savage KJ, Hernberg MM, LebbéC, Charles J, Mihalcioiu C, Chiarion-Sileni V, Mauch C, Cognetti F, Arance A, Schmidt H, Schadendorf D, Gogas H (2015) Nivolumab in previously untreated melanoma without BRAF mutation. $N$ Engl J Med 372: $320-330$.

Sharma P, Retz M, Siefker-Radtke A, Baron A, Necchi A, Bedke J, Plimack ER, Vaena D, Grimm MO, Bracarda S, Arranz JÁ, Pal S, Ohyama C, Saci A, Qu X, Lambert A, Krishnan S, Azrilevich A, Galsky MD (2017) Nivolumab in metastatic urothelial carcinoma after platinum therapy (CheckMate 275): a multicentre, single-arm, phase 2 trial. Lancet Oncol 18(3): 312-322.

Weber IS, D’Angelo SP, Minor D, Hodi FS, Gutzmer R, Neyns B, Hoeller C, Khushalani NI, Miller Jr WH, Lao CD, Linette GP, Thomas L, Lorigan P, Grossmann KF, Hassel JC, Maio M, Sznol M, Ascierto PA, Mohr P, Chmielowski B, Bryce A, Svane IM, Grob JJ (2015) Nivolumab versus chemotherapy in patients with advanced melanoma who progressed after anti-CTLA-4 treatment (CheckMate 037): a randomised, controlled, openlabel, phase 3 trial. Lancet Oncol 16(4): 375-384.

This work is published under the standard license to publish agreement. After 12 months the work will become freely available and the license terms will switch to a Creative Commons AttributionNonCommercial-Share Alike 4.0 Unported License. 